\title{
LEITE UHT TRADICIONAL X SEM LACTOSE: DIFERENÇA E ACEITAÇÃO PELOS CONSUMIDORES
}

\author{
Gabrielle da Silva Vargas Silva ${ }^{1}$; Lourran Araujo de Souza ${ }^{1}$; Amanda Antunes Porto ${ }^{1}$; Miriam \\ Thereza da Fonseca $^{1}$; Yasmin Bezerra Cavalcanti Barcellos ${ }^{1}$; Mayara Freitas Lima ${ }^{2}$; Ellen \\ Mayra Menezes Ayres ${ }^{1}$ (ellen.menezes@unirio.br)
}

1 Escola de Nutrição, Universidade Federal do Estado do Rio de Janeiro (UNIRIO), Brasil.

2 Departamento de Tecnologia de Alimentos, Universidade Federal Rural do Rio de Janeiro (UFRRJ), Brasil.

O leite sem lactose foi desenvolvido pela indústria para atender indivíduos que possuem inabilidade em digerir completamente esse dissacarídeo, buscando-se um produto com as mesmas características nutricionais e sensoriais do leite convencional, pois se sabe que esse possui grande valor nutricional, sendo fonte de proteínas de alto valor biológico, vitaminas e minerais, principalmente de cálcio. Alimentos "isentos de lactose" são aqueles em que a quantidade de lactose foi reduzida a $\leq 10 \mathrm{mg} / 100 \mathrm{~g}$ ou $\mathrm{ml}$ do alimento pronto para o consumo. Essa redução ocorre pela degradação ocasionada pela enzima lactase tendo como produto a glicose e a galactose. Com isso, consumidores intolerantes passaram a apresentar uma opção a sua dieta, ou mesmo para aqueles saudáveis caso queiram limitar a lactose. O objetivo desse trabalho foi avaliar se há diferença perceptível entre os leites UHT integral tradicional e sem lactose, e sua aceitação e intenção de compra por consumidores desses produtos. Três diferentes marcas de leite integral foram utilizadas, sendo considerada cada uma das duas versões (tradicional e sem lactose), totalizando 6 amostras. Foi realizado teste triangular, de aceitação e de intenção de compra com 70 consumidores escolhidos aleatoriamente. A aceitação foi avaliada por escala hedônica semi-estruturada de 9 pontos (1desgostei extremamente, 5- nem gostei/nem desgostei, 9- gostei extremamente) e a intenção de compra por escala semi-estruturada de 5 pontos (1- certamente compraria, 3- talvez comprasse/ talvez não comprasse, 5- certamente compraria). O número de acertos do teste triangular foi consultado na tabela ao nível de significância $5 \%$ e os outros dados submetidos à ANOVA e teste Tukey $(\mathrm{p} \leq 0,05)$. O resultado do teste triangular indicou que há diferenças perceptíveis pelos consumidores entre as versões tradicionais e sem lactose. O teste de aceitação revelou que os leites sem lactose foram mais aceitos $(6,2)$ que as versões tradicionais $(4,2)$, porém sem diferença significa entre marcas. Resultados similares foram observados na intenção de compra, com médias superiores para os leites sem lactose $(4,0)$ comparada ao convencional $(2,2)$. Pode- se concluir que diferenças entre os leites, tradicionais e sem lactose são percebidas pelos consumidores visto que o processo de quebra da lactose no leite em glicose e galactose geram diferenças sensoriais, tais como maior densidade, cor mais rosada e sabor adocicado, justificando assim sua maior aceitação e intenção de compra.

Palavras-chave: Análise sensorial; Leite UHT; Intolerância a lactose. 